\title{
Improved Clustering Technique in Marketing Sector
}

\author{
Pallavi R.Wankhade \\ ME Final Year (CSE) \\ Computer Sci \& Engg, Department \\ H.V.P.M's COET, Amravati University, India.
}

\author{
Prof. Rajeshri R. Shelke \\ Assi. Professor (CSE), Ph.D (pursuing) \\ Computer Sci \& Engg, Department \\ H.V.P.M's COET, Amravati University, India.
}

\begin{abstract}
Cluster analysis divides data into meaningful or useful groups (clusters). One of the most important problems in modern finance is finding efficient ways to summarize and visualize the stock market data to give individuals or institutions useful information about the market behavior for investment decisions. Clustering techniques that are being used in Data Mining is presented. Data mining adds to clustering the complications of very large datasets with very many attributes of different types. This imposes unique computational requirements on relevant clustering algorithms with k-means method is one of the clustering techniques. Data mining facilitates marketing sector by classifying customer demographic that can be used to predict which customer will respond to a mailing or buy a particular product and it is very much helpful in growth of business. $\mathrm{K}$ means method proposed that will improved in marketing sector and also discuss how to support clustering technique in marketing sector. Experimental results show difference between clustered and non clustered data of marketing product that represent in graphically and theoretically. These results help customer to choose the products and also it saves the time.
\end{abstract}

\section{KEYWORD}

Marketing, data mining, clustering technique.

\section{INTRODUCTION}

Data mining finds these patterns and relationships using data analysis tool and techniques to build models. It is a new kind of business information analysis technique. Its aim is to find hidden information by extracting, transforming, analyzing and modeling from large amount of data in business database. Data mining can be defined as "a decision support process in which we search for patterns of information in data". The goal of data mining is to create models for decision-making that predict future behavior based on analyses of past activity.

Advancements in computer technologies caused a rise in information production and data base system volume. To discover the data with the potential to be useful which are kept in databases and to create meaningful patterns from these are stated as data mining [2]. Businesses are in a tense competition which needs continuity in today's consumer focused markets. Businesses have to apply effective and low cost marketing strategies to be successful in these competition conditions to create effective marketing strategies true information is needed and to obtain true information future headed forecasting systems which can analyze the data in multiple dimensions are needed. In this connection, the data mining techniques are used widely in marketing field same as many other fields. Cluster analysis is unique tool, which can be wildly applied on marketing area. This set of multidimensional statistical methods often finds practical use in marketing research area.

\section{CLUSTERING PROCESS}

Cluster Analysis is the automatic process of grouping data into different groups, so that the data in each group share similar trends and pattern. The clusters which are formed are defined as the organization of datasets into homogeneous and/or well separated groups with respect to distance or equivalently similarity measure. The following diagram shows the clustering process. 


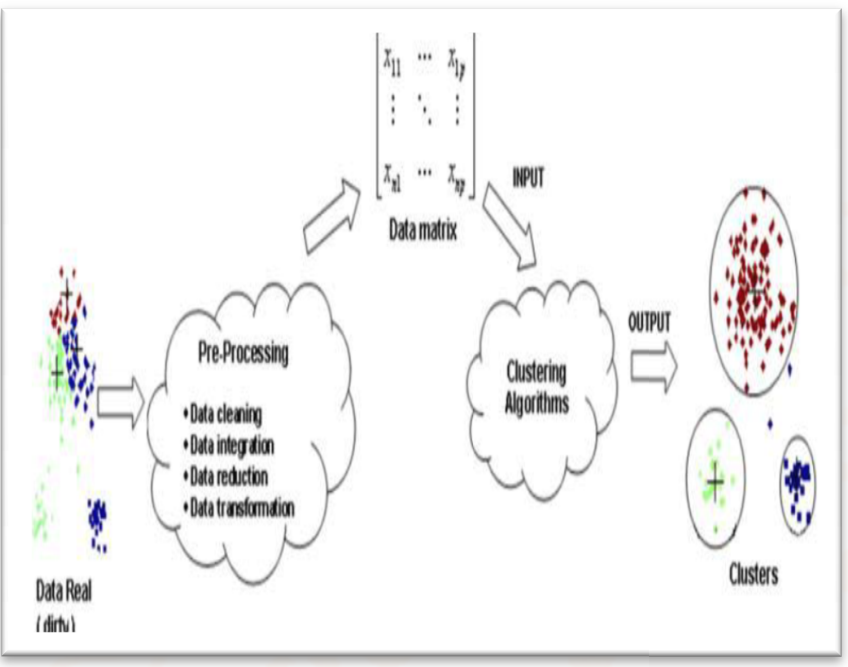

Fig. 1 Clustering Process

The clustering method presented their used class hierarchies discovered for objects forming sequences in the process of clustering sequences seen as complex objects. The approach assumed applying some traditional clustering algorithm to discover classes of sub-objects, which makes it suitable for sequences of objects described by numerical values, e.g. marketing sector.

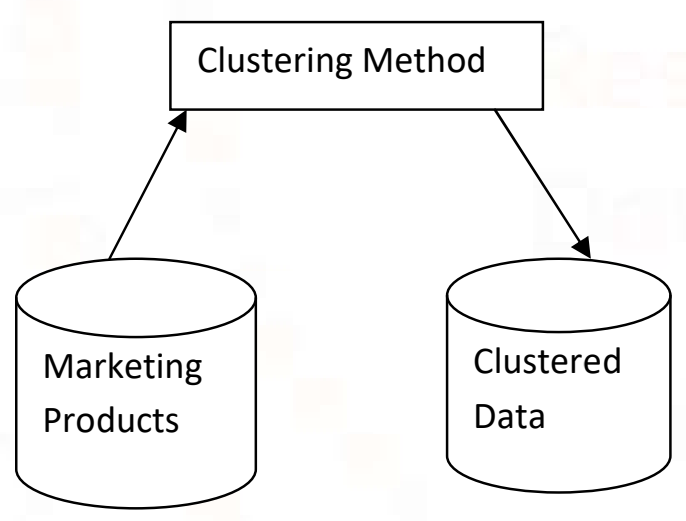

Fig. 2 Learning Part of data clustering process

In this diagram describe the whole system in which the clustering method applying on marketing products and that products are divided into the clustered data.

\section{LITERATURE REVIEW}

Radhakrishnan et al.,[1] described the Data Mining Application in Marketing. Data mining is applied to this problem by first defining what it means to be a good prospect and then finding rules that allow people with those characteristics to be targeted. Prospecting requires communication. Broadly speaking companies intentionally communicate with prospects in several ways.

Sreekumar et al.,[3] determined how customers will react to a change in interest rates, which customers will be likely to accept new product offers, what collateral would require from a specific customer segment for reducing loan losses.

\section{PROPOSED WORK}

In this work, we implement the various clustering techniques such as K-means Clustering.

Proposed Architecture:

In this diagram the user login first.

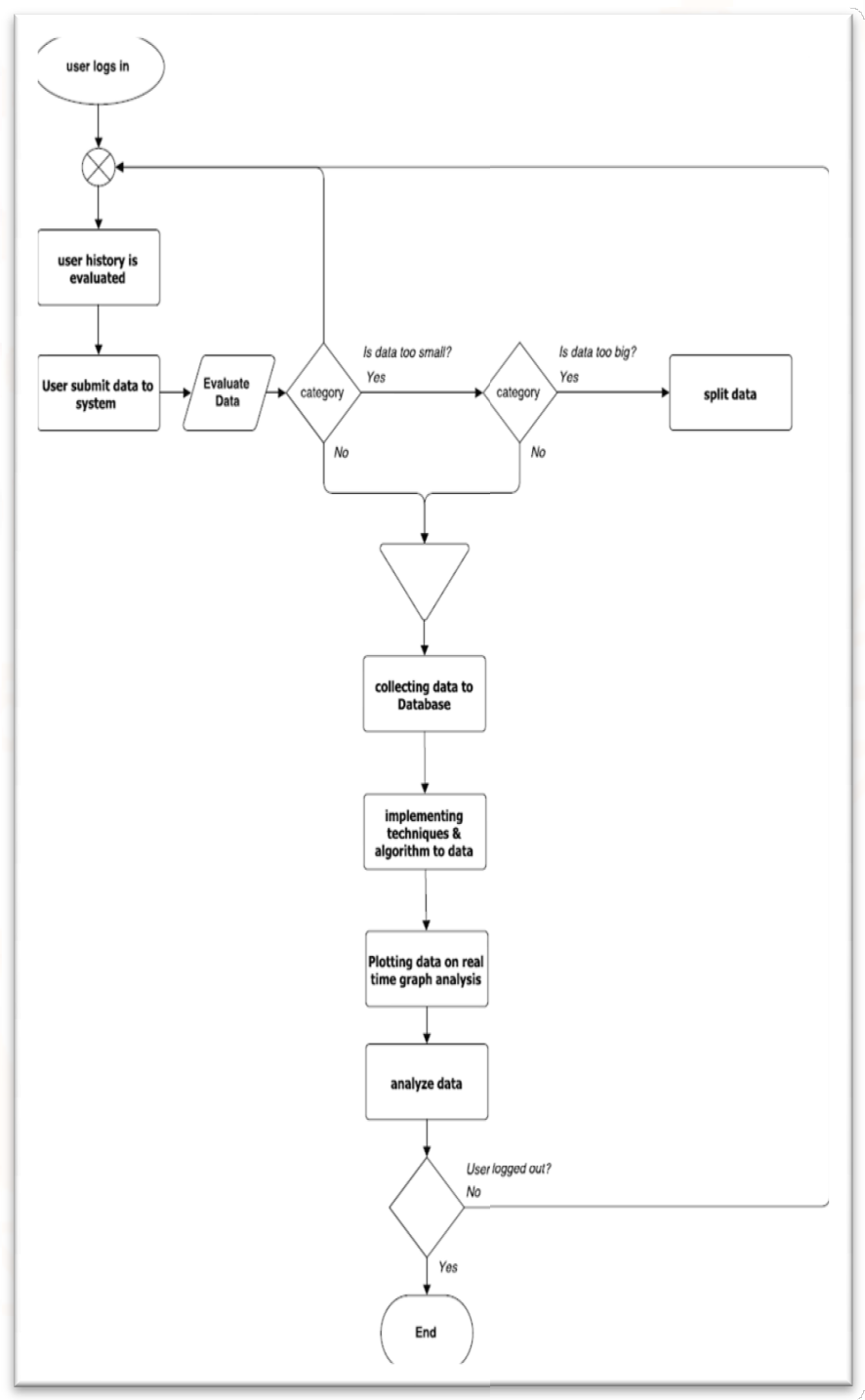

Fig. 3: Proposed Architecture Process 
After, the user login the user history is evaluated. The After the user history evaluation the user submit data to the system. Then, submitted data is process completed, the data is evaluated in to two categories first one is small data and another one is large data.

After, these data is split and categorized data are collecting data into the database and implementing the techniques and algorithm to the data and then plotting the data on real time graph analysis and analyzed the data and user got the clustered data and user are logout the system.

Behavioral clustering and segmentation help derive strategic marketing initiatives by using the variables that determine customer shareholder value. By conducting demographic clustering and segmentation within the behavioral segments, we can define tactical marketing campaigns and select the appropriate marketing channel and advertising for the tactical campaign. It is then possible to target those customers most likely to exhibit the desired behavior by creating predictive models. In this work demographic clustering algorithm is used to identify the customer clustering. In phase 1, the customer data is cleansed and developed patterns using various parameters and subsequently, in phase 2 profiled the data, developed the clusters and identified the high value low risk customers. From the experimental results it showed that the proposed approach would generate more useful pattern from large data.

The main objective of market segmentation is accurately predicting the needs of customers and thereby intern improving the profitability by procuring or manufacturing products in right quantity at time for the right customer at optimum cost. To meet these stringent requirements $k$-means clustering technique may be applied for market segmentation to arrive at an appropriate forecasting and planning decisions.

This System can be implemented using clustering techniques using with the $\mathrm{k}$ means algorithm to find out the clustered data. This system will be able to supports the $\mathrm{k}$ means algorithm for data clustering from the marketing products.

I proposed an $\mathrm{K}$ means method that will improved in marketing sector. I discuss how to support clustering technique in marketing sector. Experimental results show our difference between clustered and non clustered data of marketing product that represent in graphically and theoretically. Which helps to customer choose the products and also it saves the time. It will helpful in marketing sector.

\section{CONCLUSION}

Data mining techniques will be used to uncover hidden patterns and predict future trends and behaviours in financial markets. The competitive advantages achieved by data mining include increased revenue, reduced cost, and much improved marketplace responsiveness and awareness. We described the process of clustering from the data mining point of view. We gave the properties of a "good" clustering technique and the methods used to find meaningful partitioning. These techniques are being used in marketing sector. This study concludes that clustering techniques and algorithms become a highly active research area in data mining research.

\section{Acknowledgment}

I feel deeply indebted and thankful to all who opined for technical knowhow and helped in collection of market data also feel thankful to my guide Shelke mam and to all who directly and indirectly help me for and transactional information A special thanks to my family members for constant support and motivation.

\section{REFERENCES}

[1] Radhakrishnan B, Shineraj G, Anver Muhammed K.M ,"Application of Data Mining In Marketing", nternational Journal of Computer Science and Network, Volume 2, Issue 5, October 2013.

[2] Aslı Çaliş , Ahmet Boyaci , Kasım Baynal ,"Data mining application in banking sector with clustering and classification methods",Proceedings of the 2015 International Conference on Industrial Engineering and Operations Management Dubai, United Arab Emirates (UAE), March 3-5, 2015.

[3] Sreekumar Pulakkazhy and R.V.S. Balan, "Data Mining In Banking And It's Application A Review", Journal of Computer Science 9 (10): 1252-1259, 2013. 
[4] Dr. Sankar Rajagopal, "CUSTOMER DATA

CLUSTERING USING DATAMINING

TECHNIQUE", International Journal of Database Management Systems ( IJDMS ) Vol.3, No.4, November 2011.

[5] Rajwant Kaur, Kiran Jyoti, Rohit Kumar “ A Review Paper on Knowledge Discovery and Data Mining Techniques",International Journal of Advanced Research in Computer Science and Software Engineering ,Research Paper Available online at: www.ijarcsse.com,Volume 4, Issue 8, August 2014.

[6] Apurva Juyal, Dr. O. P. Gupta, "A Review on Clustering Techniques in Data Mining", International Journal of Advanced Research in Computer Science and Software Engineering,Volume 4, Issue 7, July 2014. 